\title{
PERUBAHAN KUALITAS LINGKUNGAN PADA HUTAN KEMASYARAKATAN DI DAERAH ALIRAN SUNGAI BABAK, PULAU LOMBOK*)
}

\author{
Environmental Quality Changes in Community Forests \\ in the Babak River Basin, Lombok Island
}

\section{Ryke Nandini', Ambar Kusumandari'2, Totok Gunawan ${ }^{3}$ \& Ronggo Sadono ${ }^{2}$}

\begin{abstract}
Community Forest $(\mathrm{HKm})$ activities in Babak Watershed have been carried out since 2007 and obtained a permit for community forest management (IUPHKm) in 2010. It cannot be denied that $\mathrm{HKm}$ has an influence on environmental quality, both quality of biophysics, economic and social environments. The purpose of this study was to determine environmental quality change of $\mathrm{HKm}$ activities in the Babak watershed in the period 2007-2015, both biophysical, economic and social environments. The study was conducted in 2015-2016 in HKm in Babak Watershed. Biophysical data obtained from field surveys and secondary data. Economic and social data were obtained by interviewing 102 respondents who were selected through purposive sampling technique. Biophysical data analysis was carried out using Soil and Water Analysis Tool (SWAT), while economic and social data were analyzed descriptively qualitatively. The results showed that in the period 2007-2015 there were changes in the quality of the environment in HKm in the Babak watershed. Changes in biophysical quality are indicated by decreases in runoff and erosion; economic quality is indicated by an increase in income and a decrease in the amount of poverty; while increasing social quality is indicated by changes in behavior in the use of forest resources. Thus, the existence of $\mathrm{HKm}$ in the Babak watershed can be developed to improve the quality of biophysical, economic and social environment.
\end{abstract}

Keywords : environmental quality, community forest, Babak watershed, Lombok Island, SWAT

\begin{abstract}
ABSTRAK
Kegiatan Hutan Kemasyarakatan (HKm) di Daerah Aliran Sungai (DAS) Babak telah dilakukan sejak tahun 2007 dan memperoleh ijin usaha pengelolaan hutan kemasyarakatan (IUPHKm) pada tahun 20I0. Tidak dapat dipungkiri bahwa HKm memberikan pengaruh terhadap kualitas lingkungan, baik kualitas lingkungan biofisik, ekonomi dan sosial. Tujuan penelitian ini adalah mengetahui perubahan kualitas lingkungan pada kegiatan HKm di DAS Babak dalam kurun 2007-20I5, baik lingkungan biofisik, ekonomi dan sosial. Penelitian dilakukan pada tahun 20I5-20I6 pada HKm di DAS Babak. Data biofisik diperoleh dari survei lapangan dan data sekunder. Data ekonomi dan sosial diperoleh dengan wawancara terhadap 102 responden yang dipilih melalui teknik purpossive sampling. Analisis data biofisik dilakukan dengan menggunakan Soil And Water Analysis Tool (SWAT), sedangkan data ekonomi dan sosial dianalisis secara deskriptif kualitatif. Hasil penelitian menunjukkan bahwa dalam kurun 2007-20I5 terdapat perubahan kualitas lingkungan pada HKm di DAS Babak. Perubahan kualitas biofisik ditunjukkan oleh penurunan limpasan dan erosi; kualitas ekonomi ditunjukkan oleh peningkatan pendapatan dan penurunan jumlah kemiskinan; sedangkan peningkatan kualitas sosial ditunjukkan oleh perubahan perilaku dalam pemanfaatan sumber daya hutan. Dengan demikian, keberadaan HKm di DAS Babak dapat dikembangkan untuk memperbaiki kualitas lingkungan biofisik, ekonomi dan sosial.
\end{abstract}

Kata Kunci : kualitas lingkungan, hutan kemasyarakatan, DAS Babak, Pulau Lombok, SWAT

Author Institution

Koresponding Author Articel History
IPeneliti Balai Penelitian dan Pengembangan Teknologi Hasil Hutan Bukan Kayu - Jalan Dharma Bhakti No. 7, Ds. Langko, Lingsar, Lombok Barat-NTB 8337I, Telp. (0370) 6175552, E-mail: bpkmataram@yahoo.co.id 2Dosen Fakultas Kehutanan Universitas Gajah Mada-Jalan Agro, Bulaksumur No.I, Kocoran, Caturtunggal, Kec. Depok, Kabupaten Sleman, Daerah Istimewa Yogyakarta 5528I

3Fakultas Geografi Universitas Gajah Mada-Jalan Kaliurang, Sekip Utara, Bulaksumur Sinduadi Sleman, Senolowo, Sinduadi, Mlati, Kabupaten Sleman, Daerah Istimewa Yogyakarta 5528I

Tel.628I24260250; rykenand@yahoo.com

Received OI March 2019; received in revised from 25 April 2019; accepted 25 April 2019; Available online since 30 April 2019

*Sudah dipresentasikan pada Seminar Nasional Fakultas Kehutanan Universitas Gajah Mada Tahun 2017 


\section{PENDAhuluAN}

Hutan kemasyarakatan $(\mathrm{HKm})$ menjadi salah satu kebijakan yang memberikan peluang pada masyarakat untuk berpartisipasi dalam pengelolaan lahan hutan. Perkembangan kebijakan $\mathrm{HKm}$ telah dimulai sejak tahun 1995, kemudian dari sisi peraturan mengalami beberapa kali pergantian yaitu dari SK Menteri Kehutanan No. 622/Kpts-II/I995, SK Menteri Kehutanan No. 677/Kpts-II/I998, SK. Menteri Kehutanan No. 3I/Kpts-II/200I dan Peraturan Menteri Kehutanan No. P.37/Menhut-II/2007 (Dipokusumo dkk., 20II). Keberadaan $\mathrm{HKm}$ telah menunjukkan manfaat bagi masyarakat dan lingkungan hutan, meskipun pada beberapa tempat justru memicu bertambahnya perambahan dan okupasi terhadap lahan hutan akibat pemahaman yang salah tentang program $\mathrm{HKm}$ (Mukhtar dkk., 20l0). Beberapa kajian menyebutkan bahwa adanya kegiatan $\mathrm{HKm}$ memberikan pengaruh positif terhadap kualitas lingkungan. Pada aspek ekologi, peranan $\mathrm{HKm}$ dapat dilihat dari potensinya dalam penurunan erosi dan peningkatan serapan karbon (Rahayu dkk., 2010; Stjepan et al., 2015). Pada aspek ekonomi, HKm berperan dalam peningkatan pendapatan dan pengentasan kemiskinan (Maryudi dan Krott, 2012; Premono dan Lestari, 2013). Adapun pada aspek sosial, $\mathrm{HKm}$ berperan dalam merubah perilaku dan meningkatkan motivasi petani (Gamaren dan Zaccai, 20I5; Furness et al., 20I5).

Kegiatan HKm di DAS Babak tersebar pada empat desa dengan luas total I.809,5 ha yaitu di desa Lantan (394 ha), Aik Berik (840 ha) dan Setiling (217,5 ha) yang secara administratif berada di Kecamatan Batukliang Utara; serta Karang Sidemen (403 ha) yang secara administratif berada di Kecamatan Batukliang. Keempat $\mathrm{HKm}$ tersebut telah memperoleh IUPHKm pada tahun 2010, dan menjadi percontohan dalam pengelolaan $\mathrm{HKm}$ di Pulau Lombok dan mampu menarik masuknya lembaga-lembaga donor seperti KOICA dan JICA untuk ikut berperan dalam berbagai kegiatan pengembangan $\mathrm{HKm}$ di Pulau Lombok. Namun demikian, sampai saat ini keberhasilan $\mathrm{HKm}$ yang berlokasi di DAS Babak lebih banyak ditunjukkan oleh hasil penelitian yang terkait dengan pendapatan sebagaimana yang dilakukan oleh Winata dkk. (20I5). Hal ini memunculkan pemikiran untuk menganalisis lebih luas peran $\mathrm{HKm}$ dalam berbagai aspek kehidupan yang lain seperti aspek biofisik dan sosial.

Salah satu tujuan awal pembentukan $\mathrm{HKm}$ di Pulau Lombok adalah untuk mengatasi kekritisan lahan yang terjadi di kawasan hutan dengan melibatkan masyarakat di sekitarnya. Kegiatan ini diawali oleh kegiatan rehabilitasi hutan dan lahan dengan pembagian bibit tanaman kepada masyarakat yang tergabung pada kelompok tani yang telah dibentuk sebelumnya. Seiring dengan perkembangannya, kegiatan $\mathrm{HKm}$ tidak hanya mampu memperbaiki tutupan lahan, namun juga meningkatkan kesejahteraan petani (Nandini dkk., 20l6). Dampak yang terjadi akibat peningkatan lahan kritis sangatlah luas, diantaranya peningkatan erosi (Cebecauer dan Hofierka, 2008; Zokaib dan Naser, 2012; Couturier et al., 2015), kerusakan tanah (Talakua, 2009), debit dan limpasan permukaan (Sari, 20II; Nunes et al., 20II; Shukla et al., 2016), serta sedimentasi (Yulianti dan Ariastita, 2012; Yan et al., 2013); berkurangnya kapasitas sungai yang menyebabkan banjir di bagian hilir (Budiati, 2006), berkurangnya kualitas udara serta biodiversitas ( $\mathrm{Li}$ et al., 20I3). Dengan adanya kegiatan $\mathrm{HKm}$, diharapkan akan membantu 
perbaikan kualitas lingkungan di kawasan hutan yang telah mengalami kekritisan lahan sebagaimana di DAS Babak.

Penelitian ini bertujuan untuk mengetahui perubahan kualitas lingkungan pada kegiatan $\mathrm{HKm}$ di DAS Babak dalam kurun 2007-2015, baik lingkungan biofisik, ekonomi dan sosial.

\section{BAHAN DAN METODE}

Penelitian dilakukan pada tahun 20152016 dengan lokasi pada kelompok tani HKm yang berada di DAS Babak. Data yang dikumpulkan berupa data biofisik, ekonomi dan sosial. Data biofisik berupa sifat fisik dan kimia tanah yang diperoleh dari survei lapangan, data curah hujan dan iklim harian tahun 2007-2014 yang diperoleh dari Badan Informasi Sumber daya Air Propinsi Nusa Tenggara Barat, serta peta-peta tematik seperti peta tanah, peta penggunaan lahan, dan peta topografi yang berasal dari instansi terkait. Data biofisik selanjutnya diolah menggunakan perangkat pemodelan Soil and Water Analysis Tools (SWAT) untuk memperoleh nilai limpasan permukaan dan erosi.

Data ekonomi dan sosial dikumpulkan melalui wawancara terhadap 102 anggota kelompok tani $\mathrm{HKm}$ di DAS Babak yang ditentukan secara purpossive. Informasi yang diperoleh dari hasil wawancara antara lain berupa total pendapatan, tingkat pendidikan, serta perilaku masyarakat dalam pemanfaatan sumber daya hutan. Analisis data sosial ekonomi dilakukan secara deskriptif kualitatif.

\section{HASIL DAN PEMBAHASAN}

\section{A. Kualitas Lingkungan Biofisik}

Analisis biofisik di DAS Babak dilakukan dengan menggunakan data penggunaan lahan tahun 2007, 2010 dan 2013 sebagai masukan dalam analisis SWAT. Tahun 2013 dianggap sebagai kondisi eksisting mengingat ketersediaan data terbaru pada saat penelitian adalah tahun 2013. Dalam kurun 2007-2013, penggunaan lahan hutan, perkebunan dan pertanian lahan kering mempunyai kecenderungan menurun, sedangkan semak belukar, pemukiman dan sawah mempunyai kecenderungan meningkat sebagaimana yang terdapat pada Tabel I.

Kegiatan HKm di DAS Babak terdapat pada jenis penggunaan lahan hutan lahan kering sekunder (HLKS), dengan luas I.809,5 ha. Hasil analisis SWAT menunjukkan bahwa pada kondisi eksisting, besarnya rata-rata limpasan permukaan pada lahan $\mathrm{HKm}$ adalah $6,54 \mathrm{~mm}$ dengan curah hujan yang terjadi sebesar 20I,17 $\mathrm{mm}$, atau nilai koefisien limpasan (C) 0,03. Dengan nilai tersebut, maka limpasan permukaan pada lahan $\mathrm{HKm}$ termasuk baik (Asdak, 20I0; Permenhut No. P.6I/MenhutII/20I4). Nilai $C$ ini termasuk baik karena hujan yang turun hanya sedikit yang menjadi limpasan.

Limpasan permukaan akan mempengaruhi erosi yang terjadi pada suatu tempat. Selain tergantung pada besarnya curah hujan (Singh, 1997), limpasan juga dipengaruhi oleh karakteristik tanah dan kerapatan vegetasi (Wischmeier \& Smith, 1978). Keberadaan $\mathrm{HKm}$ telah membantu perbaikan penutupan lahan, sehingga diduga membantu mengurangi limpasan dan erosi yang terjadi. Pada kondisi eksisting, rata-rata erosi yang terjadi pada lahan $\mathrm{HKm}$ adalah 2,34 ton/ha yang berarti masuk dalam kategori sangat ringan (Permenhut No. P.6I/Menhut-II/20I4). 
Tabel I. Perubahan penggunaan lahan di DAS Babak Table I. Changes in land use in the Babak watershed

\begin{tabular}{|c|c|c|c|}
\hline \multirow{2}{*}{ Penggunaan Lahan (Land Use) } & \multicolumn{3}{|c|}{ Luas pada tahun (Extensive in years) (hektar) } \\
\hline & 2007 & 2010 & 2013 \\
\hline $\begin{array}{l}\text { HLKP (Hutan lahan kering primer / Primary } \\
\text { dryland forest) }\end{array}$ & $4.468,80$ & 4.195,23 & $4.175,94$ \\
\hline $\begin{array}{l}\text { HLKS (Hutan lahan kering sekunder / } \\
\text { Secondary dryland forest) }\end{array}$ & $2.695,02$ & $2.723,14$ & $2.7|5,3|$ \\
\hline HTN (Hutan tanaman/Planted forest) & 824,20 & 824,20 & 816,51 \\
\hline SB (Semak belukar) & $7.009,23$ & $7.506,25$ & $7.464,10$ \\
\hline PKB (Perkebunan/Plantation) & 5,90 & - & - \\
\hline PM (Pemukiman/Habitation) & 336,14 & 604,51 & 602,5 \\
\hline SV (Savana) & 738,88 & - & - \\
\hline BA (Badan Air/ Water body) & 7,53 & 7,53 & 7,53 \\
\hline $\begin{array}{l}\text { PLK (Pertanian Lahan Kering/ Dryland } \\
\text { Agriculture) }\end{array}$ & $6.528,81$ & 640,60 & 662,16 \\
\hline $\begin{array}{l}\text { PLKC (Pertanian Lahan Kering Campuran/ } \\
\text { Mixed Dryland Agriculture) }\end{array}$ & $4.486,91$ & $3.477,89$ & $3.521,48$ \\
\hline SW (Sawah/Rice field) & $2.846,96$ & $9.969,04$ & $9.982,86$ \\
\hline Jumlah (Amount) & $29.948,39$ & $29.948,39$ & $29.948,39$ \\
\hline
\end{tabular}

Sumber: Kementerian Kehutanan, data diolah 2016

Source: Ministry of Forestry, data processed in 2016

\section{B. Kualitas Lingkungan Ekonomi}

Hasil penelitian menunjukkan bahwa rata-rata penerimaan pendapatan dari $\mathrm{HKm}$ di DAS Babak memberikan kontribusi yang cukup besar terhadap pendapatan responden yaitu $55,58 \%$, sedangkan pendapatan dari non $\mathrm{HKm}$ berkisar 44,42\%. Rata-rata pendapatan dari $\mathrm{HKm}$ adalah RpI.739.677,00 perbulan/ha. Pendapatan dari $\mathrm{HKm}$ belum mampu mencukupi kebutuhan hidup meskipun sebagian responden mempunyai pendapatan $\mathrm{HKm}$ lebih besar dari non-HKm. $\mathrm{HKm}$ dengan rata-rata luas lahan yang kurang dari 0,5 ha seperti di $\mathrm{HKm}$ Setiling dan $\mathrm{HKm}$ Karang Sidemen justru memiliki kontribusi yang lebih besar dibandingkan penerimaan pendapatan pada dua $\mathrm{HKm}$ lain yang mempunyai rata-rata luas lahan $\mathrm{HKm}$ lebih dari 0,5 ha. Hal ini tidak sejalan dengan penelitian Winata dkk. (20I5) yang menyebutkan bahwa pendapatan dipengaruhi oleh luas lahan garapan, namun sejalan dengan penelitian (Febryano, 2008) yang menyebutkan bahwa jenis komoditi memengaruhi pendapatan. Penerimaan dari $\mathrm{HKm}$ yang memberikan kontribusi terbesar adalah dari pisang, kopi dan durian. Secara keseluruhan, tanaman pisang memberikan kontribusi rata-rata $54,8 \%$, kopi $1 \mathrm{I}, 3 \%$ dan durian $8,6 \%$, sedangkan $25,3 \%$ sisanya berasal dari berbagai produk lain seperti alpukat, kelapa, nangka, sirih, pakis dan kayu bakar.

Hasil analisis menunjukkan bahwa ratarata pendapatan di lokasi penelitian adalah Rp495.179,00 per-kapita/bulan. Berdasarkan kriteria BPS tahun 2014 tentang kemiskinan di NTB khususnya Kabupaten Lombok Tengah, rata-rata pendapatan per kapita petani $\mathrm{HKm}$ di hulu DAS Babak tidak termasuk dalam kategori miskin. Jumlah petani $\mathrm{HKm}$ yang berada di bawah garis kemiskinan adalah $40,2 \%$ sedangkan yang berada di atas garis kemiskinan 59,8\%. Hal ini berarti bahwa masyarakat yang mampu memenuhi 
kebutuhan dasarnya lebih banyak dibandingkan masyarakat yang tidak mampu memenuhi kebutuhan dasarnya.

\section{Kualitas Lingkungan Sosial}

Hasil analisis tingkat pendidikan tertinggi anggota keluarga responden pada tahun 2015 dapat diketahui bahwa tingkat pendidikan yang tertinggi anggota keluarga masih didominasi oleh pendidikan SMP (34,3\%), diikuti oleh SMA (32,4\%). Adapun responden yang tidak pernah sekolah sama dengan yang menempuh perguruan tinggi yaitu 5,9\%. Peningkatan pendapatan petani juga telah meningkatkan status sosial petani dari kondisi miskin (di bawah garis kemiskinan) menjadi tidak miskin (di atas garis kemiskinan). Hal ini sejalan dengan penelitian Siregar dan Wahyuniarti (2007) yang menyebutkan bahwa ada korelasi yang signifikan antara kemiskinan dan pendidikan.

Perubahan status sosial ini juga diikuti oleh perubahan perilaku dalam pemanfaatan sumber daya karena penguasaan teknologi (Riddell \& Song, 2012), salah satu contohnya adalah perubahan pola penggunaan bahan bakar dari kayu bakar menjadi gas elpiji atau biogas (Sapkota \& Odén, 2008). Berdasarkan hasil penelitian, diketahui bahwa hanya $23,5 \%$ petani yang masih menggunakan kayu bakar. Seiring dengan perubahan perilaku petani dalam penggunaan bahan bakar dari kayu diharapkan kondisi hutan di hulu DAS Babak dapat terjaga kelestariannya.

\section{Perubahan Kualitas Lingkungan HKm dalam kurun 2007-20 I 5}

Hasil analisis terhadap data tahun 20072015, beberapa perubahan yang dapat ditemukan pada kualitas lingkungan biofisik $\mathrm{HKm}$ di DAS Babak adalah bahwa telah terjadi penurunan rata-rata nilai limpasan dan erosi, yang ditunjukkan oleh Tabel 2.

Tabel 2 menunjukkan bahwa rata-rata limpasan dari tahun 2007-20I3 mengalami penurunan, demikian pula rata-rata erosinya. Dengan demikian, dapat dikatakan bahwa keberadaan $\mathrm{HKm}$ di DAS Babak mampu menurunkan limpasan dan erosi. Hal ini sejalan dengan pendapat Nurwanti (20l4).

Pada kualitas lingkungan ekonomi, hasil analisis data menunjukkan bahwa pada kurun tahun 2007-2015 terjadi perubahan rata-rata pendapatan dan penduduk yang berada di atas garis kemiskinan. Data yang dianalisis sebagai acuan adalah data yang dikeluarkan oleh Balai Penelitian Kehutanan Mataram (2008), dimana pada tahun 2008 rata-rata pendapatan petani $\mathrm{HKm}$ adalah Rp905.130,00 per-bulan/ha. Hal ini berarti telah terjadi peningkatan 92,2\% pada tahun 2015 dimana rata-rata pendapatannya adalah Rpl.739.677,00 perbulan/ha. Jumlah penduduk yang berada di atas garis kemiskinan meningkat $40,2 \%$ yaitu dari 13,3\% pada tahun 2008 (Balai Penelitian Kehutanan Mataram, 2008) menjadi 53,5\% pada tahun 2015. Hal ini diduga terkait dengan peningkatan kontribusi pendapatan dari $\mathrm{HKm}$ yang meningkat dari rata-rata $32 \%$ pada tahun 2008 menjadi 55,6\% pada tahun 20I5. Kondisi tersebut sejalan dengan pendapat Khanal (20ll) dan Bijaya, et al. (20I5) bahwa keberadaan $\mathrm{HKm}$ telah mampu mengubah kondisi ekonomi menjadi lebih baik, yaitu meningkatkan pendapatan dan mengurangi jumlah penduduk yang berada di bawah garis kemiskinan.

Pada kualitas lingkungan sosial, perubahan tingkat pendidikan tertinggi responden diketahui dari penurunan jumlah penduduk yang tidak sekolah pada tahun 2008 sampai 2015 sebesar $46,09 \%$ sedangkan yang mencapai perguruan tinggi meningkat I,5\%. 
Tabel 2. Perubahan limpasan dan erosi pada HKm di DAS Babak

Table 2. Changes in runoff and erosion in $\mathrm{HKm}$ in the Round Watershed

\begin{tabular}{lcrrrr}
\hline \multirow{2}{*}{ Parameter } & Curah hujan & \multicolumn{3}{c}{$\begin{array}{c}\text { Analisis pada tahun } \\
\text { (Analysis in years) }\end{array}$} \\
\cline { 3 - 6 } & (Rainfall) $(\mathbf{m m})$ & \multicolumn{3}{c}{$\mathbf{2 0 1 0}$} & $\mathbf{2 0 1 3}$ \\
\cline { 3 - 6 } & 201,17 & $\mathbf{2 0 0 7}$ & 7,21 & 7,17 & 6,54 \\
Limpasan (Runoff)(mm) & 201,17 & 2,89 & 3,32 & 2,34 \\
\hline
\end{tabular}

Sumber: analisis data, 2016

Source: data analysis, 2016

Hal ini diduga terkait dengan peningkatan pendapatan responden sebagaimana yang dikemukakan oleh Riddell \& Song (2012). Peningkatan kontribusi $\mathrm{HKm}$ sebesar 55,6\% pada tahun 2015 diduga membuka peluang petani untuk meningkatkan pendidikan dan pengetahuannya yang kemudian berdampak pada perubahan perilaku dan pola pikir. Salah satunya adalah perubahan perilaku terhadap penggunaan sumber daya alam, dalam hal ini adalah kayu bakar. Pada kurun 2008-20I5, terjadi penurunan jumlah responden yang menggunakan kayu bakar sebesar $66,5 \%$, yang beralih pada penggunaan kompor gas. Peningkatan pengetahuan dan penguasaan teknologi yang diiringi oleh peningkatan pendapatan menyebabkan petani menerima program konversi minyak kepada penggunaan LPG. Dengan semakin berkurangnya ketergantungan terhadap kayu bakar, maka diharapkan kelestarian sumber daya hutan akan semakin baik.

\section{KESIMPULAN DAN SARAN}

\section{A. Kesimpulan}

Dalam kurun 2007-20I5 terdapat perubahan kualitas lingkungan pada $\mathrm{HKm}$ di DAS Babak, baik kualitas lingkungan biofisik, ekonomi dan sosial. Perubahan kualitas biofisik ditunjukkan oleh penurunan limpasan dan erosi; kualitas ekonomi ditunjukkan oleh peningkatan pendapatan dan penurunan jumlah kemiskinan; sedangkan peningkatan kualitas sosial ditunjukkan oleh perubahan perilaku dalam pemanfaatan sumber daya hutan. Dengan demikian, keberadaan $\mathrm{HKm}$ di DAS Babak dapat dikembangkan untuk memperbaiki kualitas lingkungan biofisik, ekonomi dan sosial.

\section{B. Saran}

Penelitian ini menggunakan pendekatan pemodelan yang dilakukan dengan perangkat analisis SWAT untuk memperoleh data limpasan dan erosi. Penggunaan pemodelan memberikan hasil prediksi sehingga terkadang kurang memberikan gambaran kondisi biofisik secara aktual. Dampak biofisik keberadaan $\mathrm{HKm}$ akan lebih aktual apabila dilakukan dengan pengukuran limpasan dan erosi secara langsung dalam skala plot yang dapat dilakukan pada penelitian selanjutnya.

\section{DAFTAR PUSTAKA}

Asdak, C. 20I0. Hidrologi dan Pengelolaan DAS. Cetakan Kelima. Yogyakarta: Gadjah Mada University Press.

Balai Penelitian Kehutanan Mataram. 2008. Kajian Teknis Pengelolaan Hutan Kemasyarakatan di NTB: Studi Kasus HKm di Pulau Lombok. Laporan Penelitian. Mataram. Tidak dipublikasikan. 
Bijaya, G.C.D. Sheng-kui, C., Qijie, G., Zengrang, X. and Ling-en, W. 2015. Can Community Forestry Play a Major Role in The Socioeconomic Enhancement of Poor Users in Nepal? Bulgarian Journal of Agriculture Science. 21 (2). pp.378-383.

Budiati, L. 2006. Penerapan Co-Management dalam Pengelolaan Lingkungan Menuju Pembangunan Berkelanjutan di DAS Babon, Jateng. Disertasi. Universitas Gadjah Mada. Tidak dipublikasikan.

Cebecauer, T. and Hofierka, J. 2008. The consequences of Land-cover Changes on Soil Erosion Distribution in Slovakia. Geomorphology. 98. pp. 187-198.

Couturier, A. Paroissien, JB., Mouillot, F., Raclot, D. and Bissonnais, YL. 2015. A Method for Modeling the Effects of Climate and Land Use Changes on Erosion and Sustainability of Soil in a Mediterranean Watershed (Languedoc, France). Journal of Environmental Management. I50. pp.5768.

Dipokusumo, B. Kartodihardjo, H., Darusman, D. dan Dharmawan, A.H. 20II. Kajian Dinamika Kebijakan Hutan Kemasyarakatan dan Alternatif Penyelesaian Konflik Kepentingan pada Kawasan Hutan Lindung di Pulau Lombok. Agroteknos. 2I (2-3). pp. I65-I 76.

Febryano, I. 2008. Analisis Finansial Agroforestri Kakao di Lahan Hutan Negara dan Lahan Milik. Jurnal Perennial. 4(I). pp.4I-47.

Furness, E., Harshaw, H. and Nelson, H. 2015. Community Forestry in British Columbia: Policy Progression and Public Participation. Forest Poicy and Economics. 58. Pp85-91. Available at: http://dx.doi.org//0.1016/

j.forpol.20I4.12.005

Gameren, V. and Zaccai, E. 2015. Private Forest Owners Facing Climate Change in Wallonia:Adaptive Capacity and Practices. Environmental Science and Policy. 52. Pp.5I-60. Available at: http://dx.doi.org//0.1016/j.envsci. 2015.05.004.

Khanal, B. 20II. Is Community Forestry
Decreasing The Inequality among Its Users? Study on Impact of Community Forestry on Income Distribution among Different Users Groups in Nepal. International Journal of Social Forestry. 4(2). Pp.139-152.

Li, R., Bennett, J. and Wang, X. 2013. Predicting Environmental Impacts for Assessing Land Use Change Options in Sichuan Province, China. Land Use Policy. 30(I). pp.784-790. Available at: http://dx.doi.org//0.1016/ j.landusepol.2012.05.019.

Maryudi, A. and Krott, M. 2012. Poverty Alleviation Efforts through a Community Forestry Program in Java, Indonesia. Journal of Sustainable Development. 5(2). pp.43-53. Available at: http://dx.doi//0.5539/jsd. v5n2p43

Mukthtar, Soemarno dan Hidayat, K. 2010. Pengelolaan Program Hutan Kemayarakatan Berbasis Kearifan Lokal: Studi Kasus di Kawasan Hutan Lindung Sesaot Lombok Barat. Wacana. I3(I), pp.|32-|5I.

Nandini, R., Kusumandari, A., Gunawan, T., Sadono, R. 2016. Dampak Kebijakan Hutan Kemasyarakatan terhadap Petani di Kawasan Hutan Lindung Rinjani. JEJAK: Jurnal Ekonomi dan Kebijakan. 9(I). Pp.3653. Available at: http://dx.doi.org// 0.15294/jejak.v9il .6495

Nunes, A.N., De Almeida, A.C. and Coelho, C.O.A. 2011. Impacts of Land Use and Cover Type on Runoff and Soil Erosion in a Marginal Area of Portugal. Applied Geography. 3 I (2). pp.687-699. Available at: http://dx.doi.org//0.1016/j.apgeog.2010.12 .006 .

Nurwanti, E. 2014. Evaluasi Dampak Lingkungan Hutan Rakyat Terhadap Erosi Tanah serta Sosial Ekonomi, Budaya Masyarakat Studi Kasus di Desa Rumah Gerat Kecamatan Sibiru-biru. Available at: www.researchgate.net [Diakses 14 Oktober 20I4].

Premono, B.T. dan Lestari, S. 2013. Analisis Finansial Agroforestri Kayu Bawang (Dysoxilum Mollissimum Blume) dan Kebutuhan Lahan Minimum di Propinsi 
Bengkulu. Jurnal Penelitian Sosial dan Ekonomi Kehutanan. 10(4). pp.2II-223.

Rahayu, S., Setiawan, E. dan Suyanto. 2010. Sistem Agroforestri di Kawasan Penyangga Hutan Lindung Sesaot: Potensinya sebagai Penambat Karbon. Brief No. 7. Policy Analysis Unit. World Agroforestry Centre.

Riddell, W.C. and Song, X. 2012. The Role of Education in Technology Use and Adoption: Evidence from the Canadian Workplace and Employee Survey. IZA Discussion Paper, (6377), p.p.I-34.

Sapkota, I.P. and Odén, P.C. 2008. Household Characteristics and Dependency on Community Forests in Terai of Nepal. International Journal of Social Forestry. I (2). Pp. I23-I 44.

Sari, S. 20II. Studi Limpasan Permukaan Spasial Akibat Perubahan Penggunaan Lahan (Menggunakan Model Kineros). Jurnal Pengairan. 2(2). Pp. I48-158. Available at: http://jurnalpengairan.ub.ac.id.

Shukla, S., Rathod, L.V and Khire, M.V. 2016. Effects of Urbanization on Land Use/Land Cover and Stream Flow of a Sub-Tropical River Basin of India. International Journal of Environmental, Chemichal, Ecological and Geophysical Engineering. 10(3). pp.335-343.

Singh, V.P. 1997. Effect of Spatial and Temporal Variability in Rainfall and Watershed Characteristics on Stream Flow Hydrograph. Hydrological Processes. II(I2). Pp.1649-1669.

Siregar, H. dan Wahyuniarti, D. 2007. Dampak Pertumbuhan Ekonomi terhadap Penurunan Jumlah Penduduk Miskin. Pusat Sosial Ekonomi dan Kebijakan Pertanian. pp.23-40. Available at: http://pse.litbang.pertanian.go.id/PROS_20 08_mak3.pdf.

Stjepan, P., Mersudin, A., Dźenan, B., Nenad, P.,
Makedonka, S., Dane, M. and Ŝpela, P. 2015. Private Forest owners' Willingness to Supply Woody Biomass in Selected SouthEastern European Countries. Biomass and Bioenergy. 8I. Pp.4I-I53. Available at: http://dx.doi.org/10.1016/ j.biombioe.2015.06.0II.

Winata, N.G.A.W., Basuki, P. dan Karismawan, P. 2015. Analisis Determinan Pendapatan Petani Program Hutan Kemasyarakatan $(\mathrm{HKm})$ di Kecamatan Batukliang Utara Kabupaten Lombok Tengah. Jurnal Sosial Ekonomi \& Humaniora. I(I). Pp.33-42. Available at: http://jurnal.unram.ac.id/ index.php/jseh.

Wischmeier, W. and Smith, D. 1978. Predicting Rainfall Erosion Losses: A Guide to Conservation Planning Agriculture. United States Department in cooperation with Purdue Agricultural Experimental Station.

Yan, B., Fang, N.F., Zhang, P.C. and Shi, Z.H. 2013. Impacts of Land Use Change on Watershed Streamflow and Sediment Yield: An Assessment Using Hydrologic Modelling and Partial Least Squares Regression. Journal of Hydrology. 484. pp.26-37. Available at: http://dx.doi.org//0.1016/ j.jhydrol. 2013.01 .008$.

Yulianti, R.A. dan Ariastita, P.G. 2012. Arahan Pengendalian Konversi Hutan Mangrove Menjadi Lahan Budidaya di Kawasan Segara Anakan. Jurnal Teknik ITS. I(I). Pp. I-5.

Zokaib, S. and Naser, G., 2012. Impacts of Land Uses on Runoff and Soil Erosion A Case Study in Hilkot Watershed Pakistan. International Journal of Sediment Research. 26(3). Pp.343-352. Available at: http://dx.doi.org/ 10.1016/S100I6279(II)60098-X. 